\title{
Measurements of thermal performance of cryocooler regenerators using an improved single-blow method
}

\author{
PING-HEI CHEN and ZEI-CHI CHANG \\ Department of Mechanical Engineering, National Taiwan University, Taipei, Taiwan 10617 , \\ Republic of China
}

(Received 29 February 1996 and in final form 16 August 1996)

\begin{abstract}
An improved single-blow model was employed to determine thermal performance of a cryocooler's regenerator matrix made of oversized wire-screens packed into a circular tube. The improved single-blow model includes the effects of axial conduction, heat flux into the tube wall, and Joule-Thomson expansion on the fluid temperature history at the exit of the test regenerator matrix. At the exit of the test regenerator, the variation with radius of the exit flow velocity was also investigated. In addition, the effects of oversize value and number of wire-screens on the thermal performance of the regenerator matrix are reported. (C) 1997 Elsevier Science Ltd. All rights reserved.
\end{abstract}

\section{INTRODUCTION}

It is essential to have a detailed knowledge of the heat transfer and friction characteristics of the regenerator matrix used for a cryocooler in order to improve the performance of the cryocooler. However, it is difficult to measure the local heat transfer coefficient in the regenerator matrix due to its small pore volume in the matrix. Instead, the average heat transfer coefficient between the through flow and the regenerator matrix was usually measured to evaluate the performance of cryocoolers. To measure the average heat transfer coefficient over the heat exchanger surfaces, both steady and transient heat transfer measurement methods are commonly employed. For comparison of the thermal performance between test heat exchangers, the average heat transfer coefficient is usually expressed as a dimensionless parameter, NTU $=h A / \dot{m}_{\mathrm{f}} C_{\mathrm{f}}$. For heat exchangers with NTU $>3$, a transient technique has been recommended by Liang and Yang [1] for higher accuracy. Since the heat transfer area of a regenerator matrix is large, the transient single-blow technique has been commonly adopted to determine the NTU value of regenerator matrices [2-4]. The transient single-blow technique has also been used in numerous experimental studies of compact heat exchangers [5-9].

The process of determining the NTU value using the single-blow method can be briefly described as follows. After a steady flow of fluid is established through the test regenerator matrix, the temperature of the fluid at the inlet of the test regenerator matrix is suddenly raised. As the heated fluid flows through the matrix, heat transfer takes place between the fluid and the matrix. Thus, the exit fluid temperature profile is dependent on the amount of heat transfer occurring in the regenerator matrix. With a model for the singleblow heat transfer system and an inlet fluid temperature curve, the exit fluid temperature curve can be determined by a given NTU value. Since a unique relationship exists between the NTU value of a regenerator matrix and the exit fluid temperature profile, the measured and predicted exit fluid temperature histories will agree if an accurate NTU value was selected.

The accuracy of the NTU value determination for a regenerator matrix depends on the accuracy of the model for the single-blow system. It is also important to use an adequate algorithm to match the measured and predicted exit fluid temperature curves.

Schumann [10] proposed the first single-blow model by assuming a step change in the inlet fluid temperature. Along the same step change in the inlet fluid temperature, Howard [6] also included the effect of axial conduction of test heat exchangers in the model. Pucci et al. [8] implemented Howard's model to measure the heat transfer coefficient of perforated platefin heat exchangers for NTU values ranging from 2.47 to 15.9. Liang and Yang [1] used an exponential inlet temperature curve instead of a step function but didn't include axial conduction in the single-blow analysis. Cai et al. [5] included axial conduction in their model and showed that the single-blow model should take the effect of axial conduction into account for test heat exchangers with $k_{\mathrm{e}} \times \mathrm{NTU}>0.06$ and NTU $>3$. In Mullisen and Loehrke's [7] study, the inlet fluid temperature curve could be arbitrary in their model because the fluid temperature profile in the test heat exchanger was solved by a numerical finite-difference scheme.

As to the matching technique for measured and predicted exit temperature curves, Howard [6] first 


\section{NOMENCLATURE}

$A$ frontal area $\left[\mathrm{m}^{2}\right]$

$A_{\mathrm{HT}}$ heat transfer area of wire-screen matrix $\left[\mathrm{m}^{2}\right]$

$A_{\mathrm{HT}_{\mathrm{w}}}$ heat transfer area of the tube wall $\left[\mathrm{m}^{2}\right]$

$A_{\mathrm{m}}$ heat conduction area of wire-screen matrix $\left[\mathrm{m}^{2}\right]$

$A_{\text {w }} \quad$ heat conduction area of the tube wall $\left[\mathrm{m}^{2}\right]$

C specific heat $\left[\mathrm{kJ} \mathrm{kg}^{-1}{ }^{\circ} \mathrm{C}^{-1}\right]$

$D$ inner diameter of the tube wall [m]

$d_{\mathrm{h}} \quad$ hydraulic diameter of the wire-screen, as defined in equation (9) [m]

$d_{\mathrm{m}} \quad$ wire diameter of the wire-screen [m]

$f$ friction factor, as defined in equation (11)

$h \quad$ average heat transfer coefficient of wire-screen matrix or the heat exchanger [ $\mathrm{W} \mathrm{m} \mathrm{m}^{-2} \mathrm{~K}^{-1}$ ]

$h_{\mathrm{w}} \quad$ average heat transfer coefficient of the tube wall $\left[\mathrm{W} \mathrm{\textrm {m } ^ { - 2 }} \mathrm{K}^{-1}\right]$

$k_{\mathrm{e}} \quad$ dimensionless effective thermal conductivity of wire-screen matrix, as defined in equation (4)

$k_{\mathrm{f}}^{*} \quad$ conductivity of air [W $\mathrm{m}^{-1} \mathrm{~K}^{-1}$ ]

$k_{\mathrm{s}}^{*} \quad$ conductivity of stainless steel $\left[\mathrm{W} \mathrm{m}^{-1}\right.$ $\mathrm{K}^{-1}$ ]

$k_{\mathrm{w}} \quad$ dimensionless conductivity of the tube wall, as defined in equation (4)

$L \quad$ regenerator matrix length [m]

$M \quad$ mass $[\mathrm{kg}]$

$\dot{m}_{\mathrm{f}} \quad$ mass flow rate of fluid [kg s$\left.{ }^{-1}\right]$

NTU number of transfer units of wire-screen matrix or of the heat exchanger, as defined in equation (4)

$\mathrm{NTU}_{\mathrm{w}}$ number of transfer units of the tube wall, as defined in equation (4)

$\mathrm{Nu}$ Nusselt number, as defined in equation (11)

$p \quad$ dimensionless air pressure

Re Reynolds number $\left(\dot{m}_{\mathrm{f}} d_{\mathrm{h}}\right) /(\varepsilon A \mu)$
$R_{\mathrm{tc}} \quad$ capacitance ratio of wire-screen matrix to the tube wall, as defined in equation (4)

$r \quad$ radial distance from the regenerator centerline $[\mathrm{m}]$

$S_{\max }$ maximum slope of dimensionless exit fluid temperature

$T$ dimensionless temperature

$T_{\text {fmax }}$ dimensionless heated inlet temperature at the steady state

$T_{0} \quad$ dimensionless inlet fluid temperature at $t=0$

$t \quad$ dimensionless time

$t_{i}^{*} \quad$ dimensional time variable, as defined in equation (4)

$U$ local axial velocity at the exit of wirescreen matrix $\left[\mathrm{m} \mathrm{s}^{-1}\right]$

$U_{0} \quad$ average axial velocity at the exit of wire-screen matrix $\left[\mathrm{m} \mathrm{s}^{-1}\right]$

$V_{0} \quad$ regenerator matrix volume $\left[\mathrm{m}^{3}\right]$

$x$ dimensionless axial distance from the inlet of wire-screen matrix.

Greek symbols

$\varepsilon \quad$ porosity

$\phi \quad$ shape factor

$\mu \quad$ dynamic viscosity of air $\left[\mathrm{kg} \mathrm{m}^{-1} \mathrm{~s}^{-1}\right]$

$\mu_{\mathrm{J}}$ dimensionless Joule-Thomson coefficient, as defined in equation (4)

$\tau \quad$ dimensionless time constant of inlet fluid temperature.

\section{Superscript}

* dimensional variable.

$\begin{array}{cl}\text { Subscripts } \\ \text { f } & \text { fluid } \\ \text { w } & \text { tube wall } \\ \text { m } & \text { test regenerator matrix or the heat } \\ & \text { exchanger. }\end{array}$

proposed a maximum-slope technique. Liang and Yang [1] used a five-point scheme to match the measured and predicted exit temperature curve. Mullisen and Loehrke [7] employed an algorithm to match the entire measured and predicted exit temperature curves. However, the primary shortcoming of the curve-matching scheme is that its uncertainty is higher than that for the maximum-slope scheme for high NTU values [12].

In a previous study, the authors conducted the single-blow measurements on cryocooler regenerators packed with more than 500 oversized wire-screens, which is a typical number [4]. However, the axial conduction effect was not included in the model. For test regenerator matrices with such large NTU values (NTU > 100), the single-blow model should include additional effects to more accurately describe the heat transfer system.

The present single-blow model includes the heat flux from the fluid flow into the tube wall, the axial conduction of tube wall, and the Joule-Thomson expansion for fluid flowing through the regenerator matrix. In addition, the present study investigates the effect of wire-screen oversize on the thermal performance of regenerator matrix and the variation with radius of exit flow velocity. Empirical correlations of 
test regenerator matrices friction loss and heat transfer characteristics also are presented for the use in designing the cryocoolers.

\section{THE IMPROVED MODEL}

In the present intproved model, assumptions made in the analysis are given as follows :

(1) the fluid flow is one-dimensional and steady,

(2) the material properties of wire-screen and the tube wall are constant,

(3) the axial conduction in the fluid is negligible,

(4) the conduction between wire-screen matrix and the tube wall is negligible,

(5) the thermal capacity of the fluid is negligible,

(6) the outer boundary of the tube wall is adiabatic and

(7) the pressure gradient in the fluid flow through the wire-screen matrix is linear.

Since the tube wall surrounding the regenerator matrix was assumed to be adiabatic in prior models [1-3] for the single-blow test, the only two temperatures included in the energy equations of those models were fluid temperature $T_{\mathrm{f}}^{*}$ and the test regenerator matrix temperature $T_{\mathrm{m}}^{*}$. The tube wall temperature $T_{\mathrm{w}}^{*}$ is added to the present model so that heat transfer occurring between the tube wall and fluid flow can be accounted for. Based on the energy balance, the single-blow system is described by the following energy equations :

$$
\frac{\partial T_{\mathrm{f}}}{\partial x}+\operatorname{NTU}\left(T_{\mathrm{f}}-T_{\mathrm{m}}\right)+\mathrm{NTU}_{\mathrm{w}}\left(T_{\mathrm{f}}-T_{\mathrm{w}}\right)=\mu_{\mathrm{J}}
$$

for the fluid,

$$
\frac{\partial T_{\mathrm{m}}}{\partial t}-k_{\mathrm{e}} \frac{\partial^{2} T_{\mathrm{m}}}{\partial x^{2}}+\operatorname{NTU}\left(T_{\mathrm{m}}-T_{\mathrm{f}}\right)=0
$$

for the regenerator matrix, and

$$
\frac{\partial T_{\mathrm{w}}}{\partial t}-R_{\mathrm{tc}} k_{\mathrm{w}} \frac{\partial^{2} T_{\mathrm{w}}}{\partial x^{2}}+R_{\mathrm{tc}} \mathrm{NTU}_{\mathrm{w}}\left(T_{\mathrm{w}}-T_{\mathrm{f}}\right)=0
$$

for the tube wall. In equations (1)-(3), the dimensionless variables or parameters are given by:

$$
\begin{gathered}
T_{\mathrm{f}}=\frac{T_{\mathrm{f}}^{*}-T_{0}^{*}}{T_{\mathrm{fmax}}^{*}-T_{0}^{*}} \quad T_{\mathrm{m}}=\frac{T_{\mathrm{m}}^{*}-T_{0}^{*}}{T_{\mathrm{fmax}}^{*}-T_{0}^{*}} \quad T_{\mathrm{w}}=\frac{T_{\mathrm{w}}^{*}-T_{0}^{*}}{T_{\mathrm{fmax}}^{*}-T_{0}^{*}} \\
x=\frac{x^{*}}{L} \quad t=\frac{t^{*}}{\left(M_{\mathrm{m}} C_{\mathrm{m}} / \dot{m}_{\mathrm{f}} C_{\mathrm{f}}\right)}=\frac{t^{*}}{t_{\mathrm{i}}^{*}}, \\
\mu_{\mathrm{v}}=\frac{\mu_{\mathrm{f}}^{*} L}{T_{\mathrm{fmax}}^{*}-T_{0}^{*}} \frac{\mathrm{d} p^{*}}{\mathrm{~d} x^{*}} \quad R_{\mathrm{tc}}=\frac{M_{\mathrm{m}} C_{\mathrm{m}}}{M_{\mathrm{w}} C_{\mathrm{w}}} \\
\mathrm{NTU}=\frac{h A_{\mathrm{HT}}}{\dot{m}_{\mathrm{f}} C_{\mathrm{f}}} \quad \mathrm{NTU} \mathrm{U}_{\mathrm{w}}=\frac{h_{\mathrm{w}} A_{\mathrm{HT}}}{\dot{m}_{\mathrm{f}} C_{\mathrm{f}}} \quad k_{\mathrm{e}}=\frac{k_{\mathrm{e}}^{*} A_{\mathrm{m}}}{\dot{m}_{\mathrm{f}} C_{\mathrm{f}} L} \\
\text { and } k_{\mathrm{w}}=\frac{k_{\mathrm{w}}^{*} A_{\mathrm{w}}}{\dot{m}_{\mathrm{f}} C_{\mathrm{f}} L}
\end{gathered}
$$

where the superscript * denotes the dimensional variables. Based on the assumption (7), the dimensionless Joule-Thomson coefficient $\mu_{\mathrm{J}}$ is regarded as a constant for each test regenerator matrix in the present study. Three dimensionless groups $\mathrm{NTU}_{\mathrm{w}}, R_{\mathrm{tc}}$, and $k_{\mathrm{w}}$ are added to the present model so that the heat flux into the tube wall can be considered. The energy equations are subject to the following initial conditions

$$
t=0, T_{\mathrm{f}}(x)=T_{\mathrm{m}}(x)=T_{\mathrm{w}}(x)=0-\mu_{\mathrm{J}} \cdot x
$$

and boundary conditions

$$
\left.\begin{array}{l}
x=0 T_{\mathrm{f}}=T_{\mathrm{f}}(t) \\
x=0 \frac{\partial T_{\mathrm{m}}}{\partial x}=0 \frac{\partial T_{\mathrm{w}}}{\partial x}=0 \\
x=1 \frac{\partial T_{\mathrm{m}}}{\partial x}=0 \frac{\partial T_{\mathrm{w}}}{\partial x}=0
\end{array}\right\} \text { for } t>0 .
$$

To obtain the time-dependent fluid temperature curves, equations (1)-(6) are numerically solved by a finite-difference method. A detailed discussion of this procedure can be found in Chen and Chang [11].

Equations (1)-(6) may also be solved analytically using a Laplace transformation for considerations of $k_{\mathrm{e}}=k_{\mathrm{w}}=0$ with the inlet temperature response at $x=0$

$$
T_{\mathrm{f}}(t, x=0)=1-\exp (-t / \tau) .
$$

The analytic solution is tedious and presented in Chen and Chang [11].

\section{DATA REDUCTION PROCEDURE}

When the heat flux into the tube wall is included in the single-blow model, both NTU and NTU Nust be $_{w}$ determined. In the present study, values for NTU and $\mathrm{NTU}_{\mathrm{w}}$ are determined by matching measured and predicted exit fluid temperature profiles. For a typical regenerator packed with fine mesh wire-screens (mesh number greater than 150 ), the heat transfer area of regenerator matrix is much larger than that of the tube wall; that is, the NTU value for the regenerator matrix is relatively large. For example, the NTU value is about 60 for a regenerator matrix packed with 80 wire-screens with a mesh number of 250 [3]. Since the same air flow passes through the regenerator matrix and the tube wall, the values of the average heat transfer coefficient of both the wire-screen matrix and the tube wall should be of the same order. Therefore, the ratio of $\mathrm{NTU}_{\mathrm{w}}$ to NTU should be proportional to the heat transfer area ratio of the tube wall to the wirescreen matrix.

For the inlet fluid temperature curve given in equation (7) with $\tau=0.1$, Fig. 1 shows the relationship between the maximum-slope of the exit fluid temperature profile and the NTU value for a range of $\mathrm{NTU}_{\mathrm{w}}$ values for a test regenerator matrix with $R_{\mathrm{tc}}=5, k_{\mathrm{e}}=0.001$ and $k_{\mathrm{w}}=0.001$. For a given $\mathrm{NTU}_{\mathrm{w}}$ value, the relation between $S_{\max }$ and NTU is unique. 


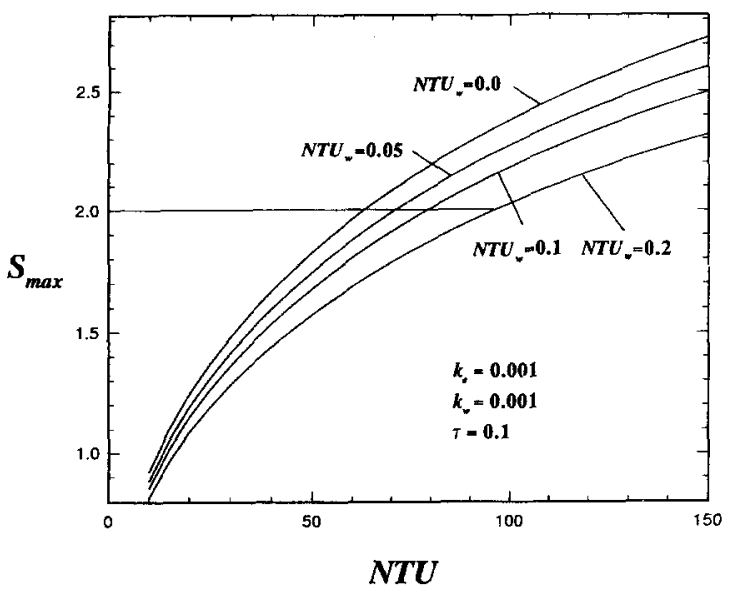

Fig. 1. Maximum slope value vs NTU for different values of $\mathrm{NTU}_{\mathrm{w}}$ for $\tau=0.1, R_{\mathrm{tc}}=5, k_{\mathrm{c}}=0.001$ and $k_{\mathrm{w}}=0.001$.

It can be observed that the variation in $S_{\max }$ with NTU becomes smoother as NTU and $\mathrm{NTU}_{\mathrm{w}}$ increase. Therefore, the uncertainty in the maximum-slope method for predicting the NTU value for the test regenerator matrix increases with both the NTU and $\mathrm{NTU}_{\mathrm{w}}$ values.

As illustrated in Fig. 1, at $S_{\max }=2.0$, the NTU ranges from 62.9 to 96.1 for $\mathrm{NTU}_{\mathrm{w}}$ value from 0.0 to 0.2 . From this it is clear that the correct NTU value for a test regenerator matrix cannot be obtained only by matching the measured and predicted $S_{\max }$ values if the $\mathrm{NTU}_{\mathrm{w}}$ has not been determined. For a given maximum-slope value in the exit fluid temperature response curve, the difference in the NTU value between cases with $\mathrm{NTU}_{\mathrm{w}}=0$ and $\mathrm{NTU}_{\mathrm{w}}=0.2$ increases with NTU itself. In addition, the increase in NTU with NTU $_{w}$ at a given $S_{\text {max }}$ indicates that the NTU value of a test regenerator matrix is underestimated if the heat flux into the tube wall is neglected in the single-blow model. However, the percentage error in NTU is lower for a regenerator matrix with a smaller NTU value. Therefore, the assumption of an adiabatic tube wall is valid only for small NTU values. On the other hand, for a test regenerator matrix with a relatively large NTU value, the maximum-slope scheme should be modified to simultaneously determine values of both NTU and $\mathrm{NTU}_{\mathrm{w}}$.

Figure 2 shows the exit fluid temperature profiles with the same maximum-slope value for various $\mathrm{NTU}_{\mathrm{w}}$ and NTU pairs at $\tau=0.1, R_{\mathrm{tc}}=5, k_{\mathrm{e}}=0.001$, $k_{\mathrm{w}}=0.001$ and $S_{\max }=2.0$. According to the results shown in Fig. 1, the NTU value increases monotonically with the $\mathrm{NTU}_{\mathrm{w}}$ value at the maximum-slope value. As indicated in Fig. 2, exit fluid temperature response curves are distinct for each pair of $\mathrm{NTU}_{\mathrm{w}}$ and NTU values. The exit fluid temperature rises more slowly for the curves with larger $\mathrm{NTU}_{\mathrm{w}}$ values.

The procedure of the present matching scheme for determining $\mathrm{NTU}_{\mathrm{w}}$ and NTU values can be described as follows. The first step is to guess an $\mathrm{NTU}_{\mathrm{w}}$ value. The exit. fluid temperature response curves are then

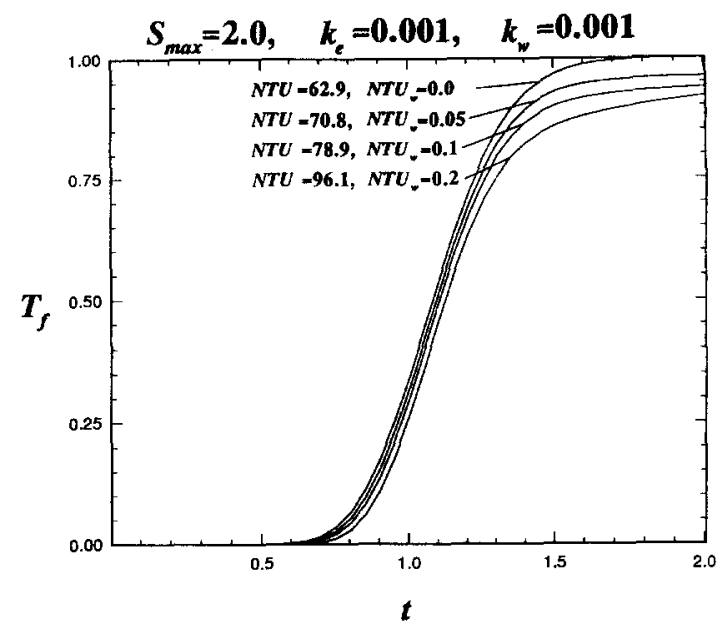

Fig. 2. Exit temperature response for different NTU and $\mathrm{NTU}_{\mathrm{w}}$ pairs with $S_{\max }=2.0$ for $\tau=0.1, R_{\mathrm{tc}}=5, k_{\mathrm{e}}=0.001$ and $k_{\mathrm{w}}=0.001$

evaluated from equations (1)-(6) for cases with various NTU values. Note that it is the actual measured inlet temperature profile to be treated as the inlet boundary condition. For the guessed $\mathrm{NTU}_{\mathrm{w}}$ value, a unique relation exists between the maximum-slope value in the exit fluid temperature curve and the NTU value. The NTU value is determined by matching the maximum-slope of the evaluated fluid temperature response to the measured one. This entire evaluated exit fluid temperature profile is then compared with the measured exit fluid temperature response curve. If both the measured and predicted exit fluid temperature profiles lie within a certain limit, the $\mathrm{NTU}_{\mathrm{w}}$ and the corresponding NTU values have both been determined. Otherwise, the procedure is repeated until both the maximum slope values and the entire temperature profiles match.

\section{EXPERIMENTAL APPARATUS}

A test facility was set up to conduct the transient single-blow measurements and to measure regenerator exit velocities. The single-blow test facility, as shown in Fig. 3, is composed of a small air tunnel, a test section, a heating system, and an automated data acquisition unit.

The steady air flow is supplied by a reciprocating compressor. The air flow rate through the tunnel is controlled by a regulator. After leaving the regulator, the air flows through a flow straightener before entering the wire-screen heating system. Downstream of the heater, the air stream flows through the test section, a downstream convergent adapter, a flange-typed orifice flow meter, and finally is discharged to the atmosphere. The flow rate of dry air flow for the singleblow measurement is measured by the calibrated orifice. The calibration of the orifice was performed in the precision measurement center of the Industrial Technology Research Institute (ITRI). 


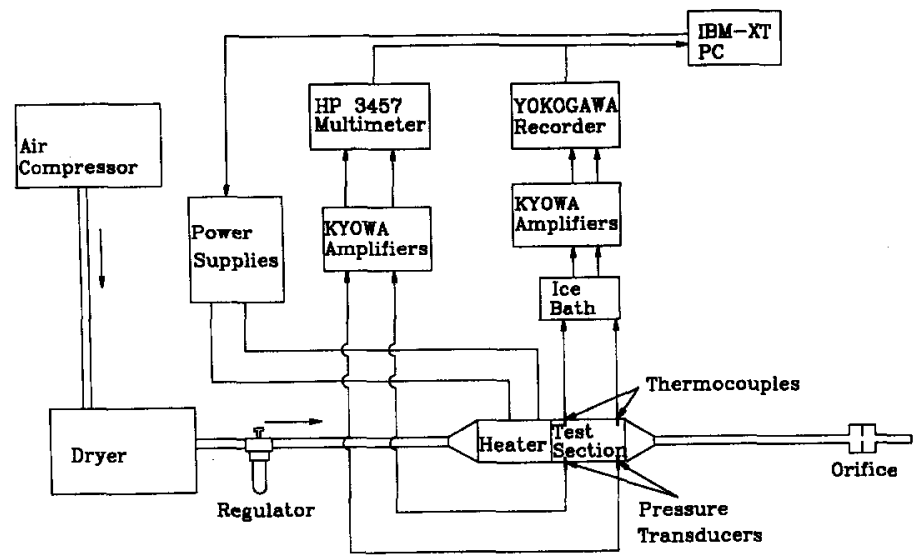

Fig. 3. Single-blow measurement and data reduction system.

Two OMEGA T-typed thermocouples of $0.025 \mathrm{~mm}$ diameter are installed in the test section to measure the air temperatures at both inlet and exit of test regenerator matrix. Both thermocouples were calibrated using an H]P2804 quartz thermometer, which has an uncertainty of $0.04 \mathrm{~K}$ for a temperature range of $293 \mathrm{~K}$ to $473 \mathrm{~K}$. Two KYOWA PG-20KU pressure transducers are used to measure the inlet and exit pressure of the test regenerator.

A wire-screen heating unit consisting of a pack of 16 wire-screen heaters and four d.c. power suppliers was constructed. Each group of four heaters was connected in parallel and powered by a d.c. power supplier as a group. On each wire-screen heater, the spacing between heating wires is only $1 \mathrm{~mm}$. The diameter and resistance of the wire are $0.01 \mathrm{~mm}$ and 126.2 $\Omega \mathrm{m}^{-1}$, respectively.

The data acquisition unit consists of a YOKOGAWA 3655E recorder, four KYOWA CDV-230 amplifiers, an IE]EE-488 interface bus, an HP 3457 multimeter and an IBM-compatible PC. The temperature and pressure signals were amplified through the KYOWA CDV-230 amplifiers. The amplified signals for the temperature and pressure were then sampled and digitized by the YOKOGAWA 3655E recorder and the HP 3457 multimeter, respectively. The sampling rate for the temperature measurements was $10 \mathrm{~Hz}$. The digital results were immediately transmitted to the PC through the IEEE-488 interface bus.

In order to study the effect of wire-screen oversize on the heat transfer performance of the regenerator matrix, four regenerators R005A, R035A, R055A and R055B were tested in the present study, where the former three are the same as those test regenerators in the authors' previous study [4]. The oversizes in the wire-screen (or the differences between the wire-screen diameter and the inner diameter of the tube) of these four regenerators are $0.05,0.35,0.55$ and $0.55 \mathrm{~mm}$, respectively. Physical properties and dimensions of these regenerators are listed in Table 1. The value of effective thermal conductivity of packed wire-screens in Table 1 is obtained from the empirical equation [13], given by

$$
k_{\mathrm{e}}^{*}=k_{\mathrm{f}}^{*}\left(k_{\mathrm{s}}^{*} / k_{\mathrm{f}}^{*}\right)^{(1-\varepsilon)^{0.59}} .
$$

The definitions of the heat transfer area of regenerator matrix $A_{\mathrm{HT}}$ and the hydraulic diameter of wire-screen $d_{\mathrm{h}}$ are the same as those in Tanaka et al. [14]. The equations for these parameters are

$$
\begin{gathered}
d_{\mathrm{h}}=\left(4 \varepsilon d_{\mathrm{m}}\right) /[\phi(1-\varepsilon)] \\
A_{\mathrm{HT}}=4(1-\varepsilon) V_{0} / d_{\mathrm{m}}
\end{gathered}
$$

where the porosity $\varepsilon$ is determined from the bulk density of stainless steel, $\phi$ is a shape factor, $V_{0}$ is the volume of the regenerator matrix and $d_{\mathrm{m}}$ is the wire diameter of the wire-screen.

The velocity measurement system consists of a three-axis positioning table, a supporting pole, a TSI 1210-T1.5 hot wire, and a TSI IFA-100 anemometer as shown in Fig. 4. The hot wire is calibrated with a TSI 1125 calibrator. The supporting pole used to hold the hot wire was fixed on the top of the three-axis table. The three-axis table serves to adjust the position of the hot wire. The precision of the three-axis table is $0.005 \mathrm{~mm}$ in each direction. The distance between the hot wire and the test regenerator was kept at 2 $\mathrm{mm}$ when the measurements were conducted.

The single-blow measurements were conducted for a range of air flow rates through the test regenerator matrix, corresponding to Reynolds number Re ranging from 39 to 225 for all test regenerator matrices. At a $95 \%$ confidence level, uncertainties from the present single-blow technique are estimated by the method proposed in Kline and McClintock [15]. The values of uncertainties for measured variables are listed in Table 2.

\section{RESULTS AND DISCUSSION}

Measured results reported here include the exit fluid temperature curves, the radial distribution of the axial velocity at the exit of each test regenerator matrix, and heat transfer characteristics for test regenerator matrices.

Figure 5 shows the measured inlet and exit fluid 
Table 1. Physical properties and dimensions of test regenerators

\begin{tabular}{|c|c|c|c|c|}
\hline Regenerator type & R005A & R035B & R055A & R055B \\
\hline Wire-screen material & SUS 316 & SUS 316 & SUS 316 & SUS 316 \\
\hline External tube material & SUS 316 & SUS 316 & SUS 316 & SUS 316 \\
\hline$L[\mathrm{~mm}]$ & 60 & 60 & 60 & 8.57 \\
\hline$D[\mathrm{~mm}]$ & 19.0 & 18.7 & 18.5 & 18.5 \\
\hline Diameter of wire-screen [mm] & 19.05 & 19.05 & 19.05 & 19.05 \\
\hline Tube thickness [mm] & 0.28 & 0.43 & 0.53 & 0.53 \\
\hline$V_{0}\left[\mathrm{~mm}^{3}\right]$ & 17011.4 & 16478.8 & 16128.2 & 2304.0 \\
\hline Mesh number of wire-screen & 200 & 200 & 200 & 200 \\
\hline$C_{\mathrm{m}}\left[\mathrm{J} \mathrm{kg}^{-1} \mathrm{~K}^{-1}\right]$ & 468 & 468 & 468 & 468 \\
\hline$k_{\mathrm{e}}^{*}\left[\mathrm{~W} \mathrm{~m}^{-1} \mathrm{~K}^{-1}\right]$ & 0.0807 & 0.0837 & 0.0859 & 0.0859 \\
\hline$d_{\mathrm{m}}[\mathrm{mm}]$ & 0.0508 & 0.0508 & 0.0508 & 0.0508 \\
\hline Number of wire-screen & 560 & 560 & 560 & 80 \\
\hline$M_{\mathrm{m}}[\mathrm{g}]$ & 38.65 & 38.65 & 38.65 & 5.52 \\
\hline$\varepsilon$ & 0.7035 & 0.6939 & 0.6873 & 0.6873 \\
\hline$d_{\mathrm{h}}[\mathrm{mm}]$ & 0.1205 & 0.1152 & 0.1117 & 0.1117 \\
\hline$A_{\mathrm{HT}}\left[\mathrm{cm}^{2}\right]$ & 3971.56 & 3971.56 & 3971.56 & 567.37 \\
\hline$M_{\mathrm{w}}[\mathrm{g}]$ & 7.662 & 11.675 & 14.316 & 2.045 \\
\hline$C_{\mathrm{w}}\left[\mathrm{J} \mathrm{kg}^{-1} \mathrm{~K}^{-1}\right]$ & 468 & 468 & 468 & 468 \\
\hline$R_{\mathrm{tc}}\left(M_{\mathrm{m}} C_{\mathrm{m}} / M_{\mathrm{w}} C_{\mathrm{w}}\right)$ & 5.04 & 3.31 & 2.79 & 2.79 \\
\hline
\end{tabular}

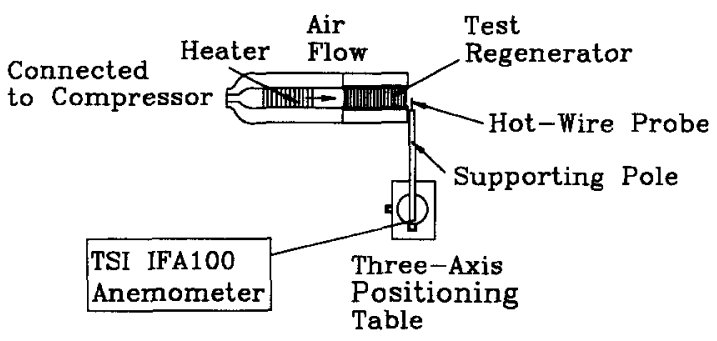

Fig. 4. Velocity measurement system.

Table 2. Uncertainty analysis for experimental data

\begin{tabular}{lc}
\hline Parameter & Uncertainty [\%] \\
\hline$U$ & 2.35 \\
$U_{0}$ & 3.28 \\
$\rho$ & 0.384 \\
$m_{\mathrm{f}}$ & 3.05 \\
$d_{\mathrm{h}}$ & 2.88 \\
$L$ & 0.167 \\
$h$ & 3.93 \\
$A_{\mathrm{HT}}$ & 3.07 \\
NTU & 2.23 \\
$R e$ & 4.32 \\
$f$ & 6.63 \\
$N u$ & 5.66 \\
\hline
\end{tabular}

temperature curves at $R e=148.56, \quad R_{\mathrm{tc}}=5$, $\mu_{\mathrm{J}}=-0.032, k_{\mathrm{c}}=0.00063$ and $k_{\mathrm{w}}=0.0013$ for regenerator R035A. The temperature drop from the inlet temperature, $T_{\mathrm{f}}=0.0$, to the exit temperature, $T_{\mathrm{f}}=-0.032$, at $t=0$ is due to the Joule-Thomson expansion as the air flow passing through the regenerator matrix. The predicted exit fluid temperature curves with the same maximum-slope value for different pairs of NTU and $\mathrm{NTU}_{\mathrm{w}}$ values are also illustrated. It is shown clearly that a large variation exists between the measured data and the predicted exit fluid temperature for $\mathrm{NTU}_{\mathrm{w}}=0$. If the NTU value is

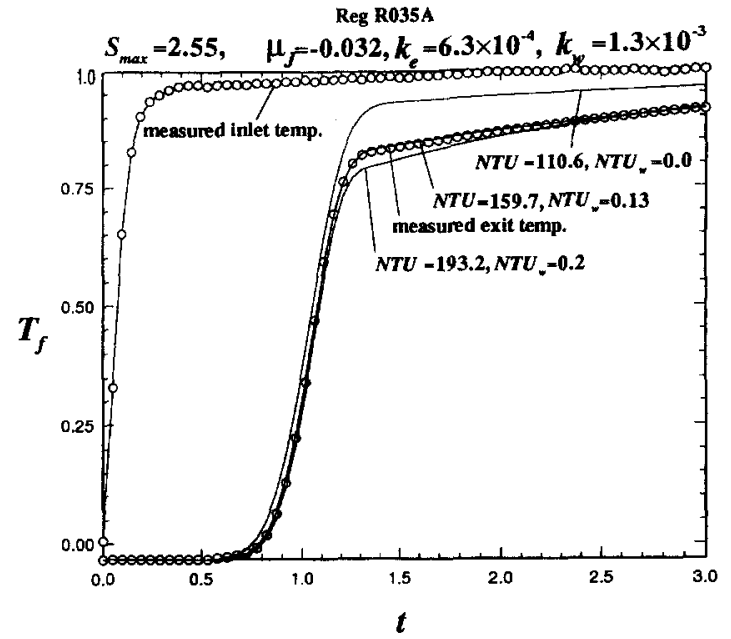

Fig. 5. Curve matching between measured and predicted exit fluid temperature histories of regenerator R035A at $R e=148.56, S_{\max }=2.55, \mu_{\mathrm{J}}=-0.032, k_{\mathrm{e}}=6.3 \times 10^{-4}$ and $k_{\mathrm{w}}=1.3 \times 10^{-3}$

evaluated using the maximum-slope method alone, an NTU is underestimated by $30.7 \%$ because of the adiabatic tube wall assumption. In addition, the curve-matching scheme may fail to accurately determine the NTU value of test regenerator matrix if the Joule-Thomson expansion is not included in the single-blow model.

Table 3 shows the effect of axial conduction on the determination of NTU and $\mathrm{NTU}_{\mathrm{w}}$ values. The NTU and $\mathrm{NTU}_{\mathrm{w}}$ values listed in the second and third columns are determined without consideration of axial conduction, which are given by the authors' previous study [4]. The NTU and NTU $_{w}$ values listed in the fourth and fifth columns are determined with consideration of axial conduction in the present study. Since the single-blow test model without the consideration of axial conduction will result in an under- 
Table 3. Effect of axial conduction on the NTU value

\begin{tabular}{|c|c|c|c|c|c|c|}
\hline $\operatorname{Re}$ & \multicolumn{2}{|c|}{$k_{\mathrm{e}}=0, k_{\mathrm{w}}=0$} & \multicolumn{2}{|c|}{$k_{\mathrm{e}}>0, k_{\mathrm{w}}>0$} & $k_{\mathrm{e}} \times 10^{3}$ & $k_{\mathrm{w}} \times 10^{3}$ \\
\hline \multicolumn{7}{|c|}{ Reg R005A } \\
\hline 45.39 & 232.03 & 0.24 & 293.36 & 0.20 & 2.04 & 3.29 \\
\hline 69.80 & 178.89 & 0.17 & 213.31 & 0.16 & 1.33 & 2.15 \\
\hline 93.26 & 157.40 & 0.17 & 179.33 & 0.15 & 1.00 & 1.61 \\
\hline 103.71 & 148.96 & 0.15 & 167.35 & 0.14 & 0.90 & 1.45 \\
\hline 122.17 & 144.35 & 0.15 & 158.21 & 0.14 & 0.76 & 1.22 \\
\hline 138.05 & 143.20 & 0.14 & 151.67 & 0.13 & 0.68 & 1.09 \\
\hline 154.34 & 134.76 & 0.13 & 142.84 & 0.12 & 0.61 & 0.98 \\
\hline 170.09 & 124.39 & 0.11 & 129.87 & 0.11 & 0.55 & 0.89 \\
\hline 189.62 & 118.64 & 0.11 & 122.83 & 0.10 & 0.49 & 0.79 \\
\hline 212.31 & 107.51 & 0.10 & 117.36 & 0.10 & 0.44 & 0.71 \\
\hline \multicolumn{7}{|c|}{ Reg R035A } \\
\hline 41.97 & 279.69 & 0.24 & 336.85 & 0.20 & 2.19 & 4.52 \\
\hline 69.57 & 213.28 & 0.21 & 228.91 & 0.19 & 1.33 & 2.75 \\
\hline 93.56 & 178.89 & 0.15 & 196.78 & 0.15 & 0.99 & 2.05 \\
\hline 111.21 & 168.15 & 0.15 & 185.25 & 0.14 & 0.84 & 1.73 \\
\hline 135.58 & 156.25 & 0.14 & 173.35 & 0.13 & 0.69 & 1.42 \\
\hline 148.56 & 148.19 & 0.13 & 159.74 & 0.13 & 0.63 & 1.30 \\
\hline 162.78 & 141.28 & 0.13 & 148.56 & 0.11 & 0.57 & 1.19 \\
\hline 185.85 & 146.65 & 0.13 & 150.13 & 0.12 & 0.50 & 1.04 \\
\hline 206.28 & 128.62 & 0.12 & 131.77 & 0.11 & 0.45 & 0.94 \\
\hline 224.98 & 123.24 & 0.10 & 124.85 & 0.10 & 0.42 & 0.86 \\
\hline \multicolumn{7}{|c|}{ Reg R055A } \\
\hline 39.03 & 313.28 & 0.29 & 353.79 & 0.23 & 2.37 & 6.42 \\
\hline 69.06 & 235.94 & 0.22 & 273.11 & 0.19 & 1.35 & 3.65 \\
\hline 89.55 & 192.32 & 0.16 & 226.88 & 0.15 & 1.04 & 2.82 \\
\hline 105.23 & 173.90 & 0.14 & 195.25 & 0.14 & 0.89 & 2.40 \\
\hline 126.96 & 170.06 & 0.15 & 189.74 & 0.14 & 0.73 & 1.98 \\
\hline 148.65 & 162.77 & 0.13 & 180.46 & 0.13 & 0.63 & 1.69 \\
\hline 159.31 & 167.76 & 0.16 & 183.67 & 0.14 & 0.58 & 1.58 \\
\hline 171.48 & 158.55 & 0.13 & 169.81 & 0.12 & 0.54 & 1.47 \\
\hline 182.55 & 151.64 & 0.12 & 160.96 & 0.12 & 0.51 & 1.38 \\
\hline 204.21 & 143.20 & 0.12 & 150.69 & 0.11 & 0.46 & 1.24 \\
\hline 216.66 & 132.07 & 0.11 & 138.43 & 0.10 & 0.43 & 1.16 \\
\hline
\end{tabular}

estimated result of the NTU value, the NTU value of $k_{\mathrm{e}}=0$ is smaller than that of $k_{\mathrm{e}}>0$ at a given $R e$. And this trend increases with an increase of NTU value.

However, the effect of the tube wall is similar to that of the axial conduction, which will also make the maximum slope of the exit temperature curve decrease. If the effect of axial conduction is neglected, the effect of axial conduction will be consequently counted in the tube wall effect, that is, the effect of the tube wall will be overestimated. In other words, the $\mathrm{NTU}_{\mathrm{w}}$ value of $k_{\mathrm{z}}=0$ is larger than that for $k_{\mathrm{e}}>0$ for a given $R e$ as shown in the table.

In order to investigate the effect of oversize, the exit velocity distributions along the radial direction for regenerators R005A, R035A and R055A were measured, and the measured results are compared in Fig. 6. The local exit velocity $U$ was directly measured by the hot wire aremometer. The average velocity $U_{0}$

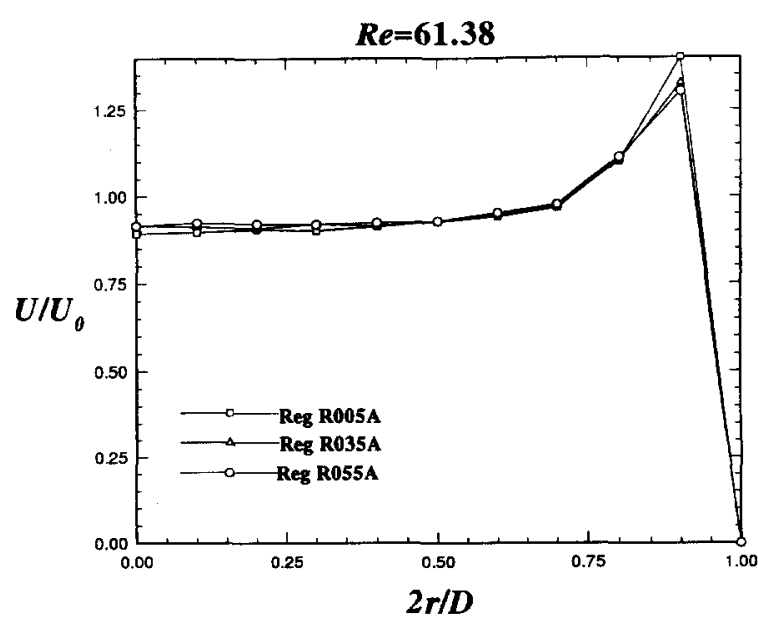

Fig. 6. Effect of the number of wire-screen on the correlation between $\mathrm{Nu}$ and $\mathrm{Re}$. 
was calculated by integrating the measured local exit velocities along the radial direction. The measurement was conducted at $R e=61.38$ for all three test regenerators.

Because of the no slip boundary condition, velocities at the tube walls are zero, as shown in Fig. 6. The maximum velocity occurs at a small offset from the tube wall of the test regenerator as expected. The velocity profile at the core region appears to be uniform. The velocity distributions for the three test regenerators are similar. However, regenerator R005A has the lowest $U / U_{0}$ value in the core region and the highest maximum $U / U_{0}$ value near the circumference of the test regenerator. However, the difference in the velocity profiles between regenerators with large oversizes in wire-screens, R035A and $\mathrm{R} 055 \mathrm{~A}$, is smaller.

Figures 7 and 8 show the friction loss and the heat transfer characteristics of the test regenerators, which are presented in terms of friction factor $f$ and Nusselt number $N u$, respectively. Definitions of $f$ and $N u$ are given by

$$
\begin{gathered}
f=\frac{\Delta p \cdot d_{\mathrm{h}}}{0.5 \rho U^{2} L} \\
N u=\frac{h d_{\mathrm{h}}}{k_{\mathrm{f}}^{*}} .
\end{gathered}
$$

Among the three regenerators R005A, R035A and $\mathrm{R} 055 \mathrm{~A}$, it is apparent that the one with the largest oversize in wire-screens, R055A, has the highest friction loss and heat transfer at a given Reynolds number. However, the difference between regenerators R035A and R055A is small. There is also little difference in the friction loss and heat transfer characteristics between regenerators R055A and $\mathrm{R} 055 \mathrm{~B}$, which are made of the same size and material, but the former has 560 wire-screens while the latter has only 80 .

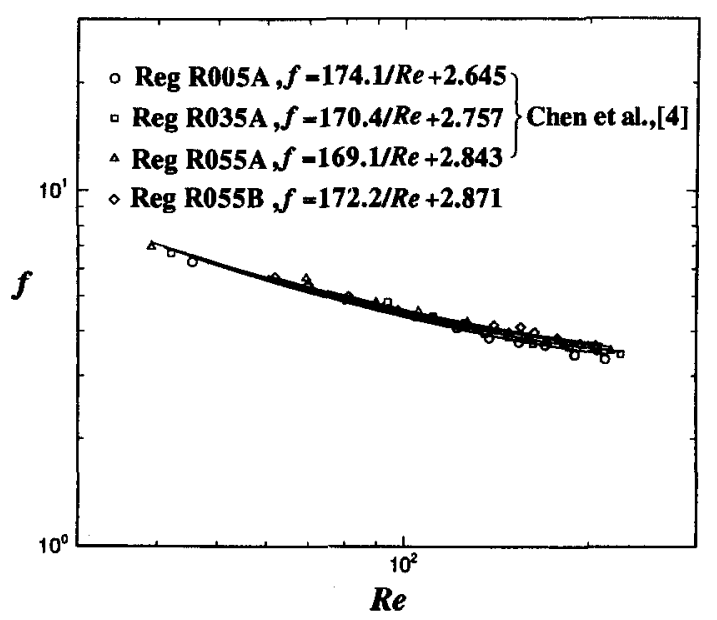

Fig. 7. Correlation between $f$ and $R e$.

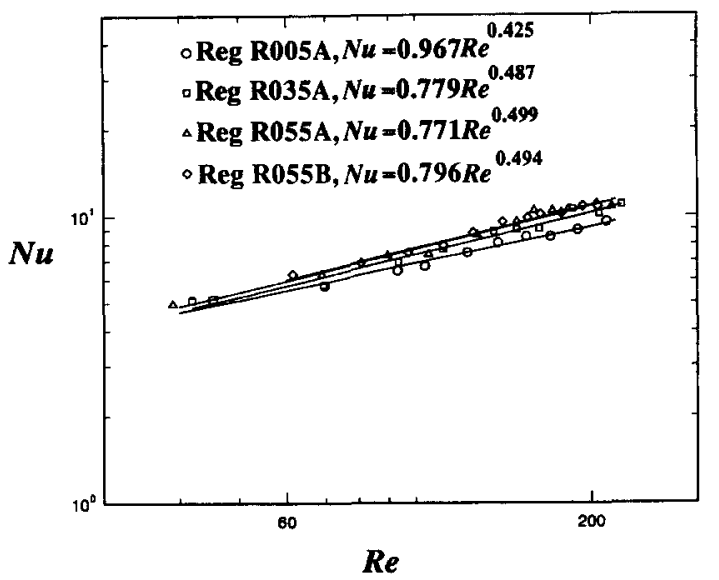

Fig. 8. Correlation between $\mathrm{Nu}$ and $\mathrm{Re}$.

\section{CONCLUSIONS}

The thermal performances of four test regenerators R005A, R035A, R055A and R055B are measured through the improved single-blow test model. The velocity measurement system was also set up to observe the exit velocities of the three regenerators with 560 wire-screens. Three main topics are included in this present study, namely, the effect of the number of wire-screens, axial conduction, and wire-screen oversize, which are briefly summarized as follows:

(1) The number of wire-screens makes no effect in this present study. The friction loss and heat transfer characteristics of two regenerators R055A and R055B with different numbers of wire-screen are quite close.

(2) If the effect of axial conduction is considered in the improved single-blow test model, the NTU value will increase and the effect gets stronger as the NTU value increases.

(3) The oversize effect will increase the thermal performance of the test regenerator but this trend becomes less pronounced as the oversize increases.

Acknowledgement-The authors would like to express their appreciation for the financial support by the Energy Council of the Ministry of Economy in Taiwan under the Grant Number $832 Z 6$.

\section{REFERENCES}

1. C. Y. Liang and W. J. Yang, Modified single-blow technique for performance evaluation on heat transfer surfaces, $A S M E J$. Heat Transfer 97, 16-21 (1975).

2. G. Walker and V. Vasishta, Heat-transfer and flowfriction characteristics of dense-mesh wire-screen Stirling-cycle regenerators, Adv. Cryogenic Engng 16, 324332 (1971).

3. K. Hamaguchi, S. Takahachi and H. Miyabe, Thermal performance of regenerator matrix, JSME Ser. $B$ (in Japanese) 49, 2001-2010 (1983).

4. P. H. Chen, Z. C. Chang and B.-J. Huang, Effect of oversize in wire-screen matrix to the matrix-holding tube on regenerator thermal performance, $J$. Cryogenics 36, 365-372 (1996).

5. Z. H. Cai, M. L. Li, Y. W. Wu and H. S. Ren, A modified selected point matching technique for testing compact 
heat exchanger surfaces, Int. J. Heat Mass Transfer 27, 971-978 (1984).

6. C. P. Howard, The single-blow problem including the effect of longitudinal conduction, ASME Paper No. 64GT2-11 (1964).

7. R. S. Mullisen and R. I. Loehrke, A transient heat exchanger evaluation test for arbitrary fluid inlet temperature variation and longitudinal core conduction, ASME J. Heat Transfer 108, 370-376 (1986).

8. P. F. Pucci, C. P. Howard and C. H. Piersall, The singleblow transient testing technique for compact heat exchanger surfaces, ASME J. Engng Power 89, 29 -40 (1967).

9. Y. Yagi and S. Mochizuki, Development of a modified single-blow method-an application to parallel-plate heat-transfer surfaces, Heat Transfer-Jap. Res. 20, 646 655 (1991).

10. T. E. W. Schumann, Heat transfer: a liquid flowing through a porous prism, J. Franklin Inst. 28, 405-416 (1929).
11. P. H. Chen and Z. C. Chang, An improved model for the single-blow measurement including the non-adiabatic tube wall effect, Int. Commun. Heat Mass Transfer 23, 55-68 (1996).

12. P. H. Chen and Z. C. Chang, Measurements of thermal performance of the regenerator of a cryocooler with high NTU value, Proc. Instn Mech. Engrs, Part C J. Mech. Engng Sci. 210, 341-352 (1996).

13. E. G. Alexander, Jr., Structure-property relationship in heat pipe wicking material, Ph.D. Thesis, Department of Chemical Engineering, North Carolina State University, Raleigh, NC (1972).

14. M. Tanaka, I. Yamashita and F. Chisaka, Flow and heat transfer characteristics of Stirling engine regenerator in oscillating flow, JSME Int. J. Ser. II 33, 283-289 (1990)

15. S. J. Kline and F. A. McClintock, Describing uncertainties in single sample experiments, Mech. Engng 75 , 3-8 (1953). 